\title{
Analisis Nilai Spiritual dalam Pembentukan Karakter pada Buku Cerita Rakyat Karya Wirodarsono
}

\author{
Naelil Maziyah ${ }^{1,}$ Rahmat Rais ${ }^{2}$, Kiswoyo $^{3}$ \\ 1,2,3 Jurusan Pendidikan Guru Sekolah Dasar, Universitas PGRI Semarang \\ e-mail: naelilmazi5@gmail.com
}

\begin{abstract}
Abstrak
Penelitian ini bertujuan untuk mengetahui dan mendeskripsikan nilai-niali spiritual yang dapat membentuk karakter siswa dalam Buku Cerita Rakyat Joko Dolok Karya Wiradarsono, untuk mengetahui seberapa berpengaruhnya nilai spiritual dalam buku cerita yang dapat membentuk nilai karakter serta untuk mengetahui bagaimana sekolah menanamkan nilai karakter pada anak didik. Penelitian ini dilatarbelakangi oleh kemajuan teknologi yang dapat mempengaruhi berkurangnya minat baca siswa terhadap buku cerita rakyat serta menggeser tata nilai dalam kehidupan. Akibatnya, kehidupan manusia menjadi kering spiritualitas, bahkan keimanan pada Dzat Yang Maha Kuasa juga mulai luntur. Jenis penelitian ini adalah kualitatif dengan metode deskriptif. berdasarkan hasil analisis peneliti, buku cerita rakyat Joko Dolok mengandung 34 nilai spiritual yang dapat membentuk karakter siswa. Nilai-nilai spiritual dan nilai-nilai karakter tersebut dapat dilihat dari kutipan dalam penokohan, dan dibuktikan dari indikator iman, ibadah, dan akhlak serta indikator 18 nilai karakter, beberapa point yang mempengaruhi nilai spiritual dalam buku cerita dapat membentuk nilai karakter yaitu dari lingkungan, banyaknya nilai spiritual yang ada didalam buku tersebut dan isi atau alur dari cerita tersebut. Dan tiga cara menanamkan nilai karakter pada siswa yaitu sebelum pembelajaran dimulai, saat pembelajaran dimulai dan saat diluar jam pembelajaran. Penelitian yang telah dilakukan mengenai nilai spiritual dalam buku cerita rakyat berkaitan dengan karakter siswa itu sendiri, guru bisa menjadikan buku cerita rakyat sebagai media untuk membentuk karakter, media pembelajaran yang menyenangkan sehingga siswa tidak bosan dalam mengikuti pelajaran.
\end{abstract}

Kata kunci : Nilai Spiritual, Nilai Karakter, Buku Cerita Rakyat

\begin{abstract}
This researcher has the purpose to know and describe the moral value which can build the carracter of the students from Joko Dolok storybooks that written by Wiradarsono, to know how much the effectiveness of moral value from Joko Dolok storybooks and how the school system apply moral value to the students. Background of this research is how to know the influential of tecnology can discharge the students interest for reading the book story and change the moral value of live. Actually, the live of humanity be the low of moral value and the believable of godness. the type of tis research is qualitative and discriptive metod. based on the result of analysis of the researcher, Joko Dolok bstorybooks have 34 moral value which build the carracteristics of the students. the moral value and carracterization can be seen from the quotations of the carracter of the story, and prroven by indicator of faith, praying, and worship of 18 moral value, some points of moral value from the storybooks can build the carracter values of environment. many carracter of spiritual that contained in this storybooks. there are three ways to apply carracteristic value to the students, before starting the lessons, doing the lesssons of teaching, and out of the class room. The research of moral value of the storybooks that have done is related ro the carracter of the students. the teacher make the storybooks as a media for building the carracter tobe the enjoyfull media. expect, the students can follow the lesson.
\end{abstract}

Keywords: Spiritual Value, Character Value, Folklore Book 


\section{Pendahuluan}

Pendidikan merupakan suatu proses yang mencakup tiga dimensi, individu, masyarakat atau komunitas nasional dari individu tersebut, dan seluruh kandungan realitas, baik material maupun spiritual yang memainkan peranan dalam menentukan sifat, nasib, bentuk manusia maupun masyarakat. Pendidikan lebih dari sekedar pengajaran, yang dapat dikatakan sebagai suatu proses transfer ilmu, transformasi nilai, dan pembentukan kepribadian dengan segala aspek yang dicakupnya. Dengan demikian pengajaran lebih berorientasi pada pembentukan spesialis atau bidangbidang tertentu, oleh karena itu perhatian dan minatnya lebih bersifat teknis. Pendidikan merupakan suatu proses yang diperlukan untuk mendapatkan keseimbangan dan kesempurnaan dalam perkembangan individu maupun masyarakat. Penekanan pendidikan dibanding dengan pengajaran terletak pada pembentukan kesadaran dan kepribadian individu atau masyarakat di samping transfer ilmu dan keahlian. Dengan proses semacam ini suatu bangsa atau negara dapat mewariskan nilai-nilai keagamaan, kebudayaan, pemikiran dan keahlian kepada generasi berikutnya, sehingga mereka betul-betul siap menyongsong masa depan kehidupan bangsa dan negara yang lebih cerah (Nurkholis ,2013).

Pasal 1 UU SISDIKNAS no. 20 tahun 2003 disebutkan bahwa Sistem Pendidikan Nasional adalah keseluruhan komponen pendidikan yang saling terkait secara terpadu untuk mencapai tujuan pendidikan nasional. Berangkat dari bunyi pasal ini dapat diketahui bahwa pendidikan adalah sistem yang merupakan suatu totalitas struktur yang terdiri dari komponen yang saling terkait dan secara bersama menuju kepada tercapainya tujuan (Soetarno, 2003: 2). Adapun komponen-komponen dalam pendidikan nasional antara lain adalah lingkungan, sarana-prasarana, sumberdaya, dan masyarakat. Komponen-komponen tersebut bekerja secara bersama-sama, saling terkait dan mendukung dalam mencapai tujuan pendidikan. Tujuan pendidikan nasional yang dirumuskan dalam UU SISDIKNAS adalah untuk mengembangkan potensi anak didik agar menjadi manusia yang beriman dan bertakwa kepada Tuhan Yang Maha Esa, berakhlak mulia, sehat, berilmu, cakap, kreatif, mandiri, dan menjadi warga Negara yang demokratis serta bertanggung jawab (Munirah ,2015).

Pada satu sisi, perkembangan dunia IPTEK yang demikian mengagumkan itu memang telah membawa manfaat yang luar biasa bagi kemajuan peradaban umat manusia. Kemajuan teknologi adalah sesuatu yang tidak bisa dihindari dalam kehidupan ini, karena kemajuan teknologi akan berjalan sesuai dengan kemajuan ilmu pengetahuan (Ngafifi, 2014). Di sisi lain, manusia tidak bisa menipu diri sendiri akan kenyataan bahwa teknologi mendatangkan malapetaka dan kesengsaraan bagi manusia modern. Kemajuan teknologi informasi dan komunikasi sering menjadi penghalang tumbuh dan berkembangnya minat baca anak dan cenderung akan mengubah karakter pada anak. Media digital dan elektronik telah berhasil menarik perhatian kebanyakan anak Indonesia yang secara langsung dan tidak langsung memicu aktivitas keseharian mereka lebih terkonsentrasi pada pemanfaatan media tersebut. Bahkan media telah mengambil alih peran orangtua dalam mengembangkan kepribadian anak. Hal ini sejalan dengan pandangan Yaumi (2008) yang mengatakan bahwa anak yang hidup di perkotaan memiliki kebiasaan nonton televisi dan bermain video game, playstation, dan internet yang rasionya 19 kali berbanding satu kali berbicara dengan orang tua.

Melalui angket yang telah dibagikan kepada siswa kelas $2-5$ di SD N Lamper Tengah 02 Semarang sebanyak 30 angket, hampir 75\% siswa SD N Lamper tengah 02 Semarang sudah tidak minat lagi membaca buku cerita rakyat yang telah diketahui bahwa buku cerita rakyat telah turun temurun di lingkungan masyarakat sekitar. Perkembangan zaman yang begitu cepat membuat siswa lebih suka menghabiskan waktu mereka untuk bermain smartphone dari pada membaca buku cerita atau menghabiskan waktu bersama teman sebayanya dengan melakukan permainan tradisional. Padahal dengan membaca cerita rakyat merupakan salah satu bentuk melestarikan dan mempertahankan budaya lokal tetapi budaya membaca cerita rakyat sudah sangat jarang di temui pada anak-anak SD saat ini. Pada dasarnya dengan membaca atau mendengarkan cerita rakyat dapat membuat anak-anak usia SD secara tidak langsung. Dengan membaca buku cerita rakyat secara tidak langsung karakter anak terbentuk lebih baik, karena dalam buku cerita rakyat banyak mengandung nilai-nilai spiritual yang dapat membentuk karakter anak lebih baik, dan anak bisa mengaplikasikannya dalam kehidupan sehari-hari.

Semua agama mengajarkan tentang moral, nilai, etika, pentingnya melakukan perbuatan baik, tidak di perbolehkan untuk melakukan perbuatan jelek, dan berbagai ajaran spiritualitas. Sikap spiritual adalah sikap yang menyangkut moral yang mampu memberikan pemahaman 
untuk membedakan sesuatu yang benar dan yang salah berdasarkan keimanan dan ketakwaan kepada Tuhan YME (Gusviani, 2016). Pada tahun 2006-2007 Yosi Amram melakukan penelituan tentang nilai-nilai spiritualitas yang tercermin dari ajaran moral, nilai, dan etika dengan melibatkan Beberapa agam seperti Buddha, Hindu, Kristen, Islam, Yahudi, Non-Dual, Shamani, Taoisme, dan Yoga. Kemudian, dia merumuskan tujuh nilai-nilai dasar spiritual yang terdapat dalam semua agama tersebut, yaitu: (1) kesadaran, (2) keanggunan, (3) kebermaknaan, (4) nilai yang melampaui di atas segalanya (transcendence), (5) kebenaran, (6) kedamaian, dan (7) kebijaksanaan (Amram, 2007).

Karakter dalam bahasa agama disebut dengan akhlak. Seperti dikatakan oleh Akramulla Syed (2011), akhlak merupakan istilah dalam bahasa Arab yang merujuk pada prakti-praktik kebaikan, moralitas dan perilaku yang baik. Istilah akhlak sering diterjemahkan dengan perilaku islami (islamic behavior), sifat atau watak (disposition), perilaku baik (good conduct), kodrat atau sifat dasar (nature), perangai (temper), etika atau tata susila (ethics), moral, dan karakter. Semua kata tersebut merujuk pada karakter yang dapat dijadikan suri teladan yang baik bagi orang lain. Di sinilah yang dimaksudkan oleh Allah dalam ayat Al-Qur'an berikut ini:

"Sesungguhnya telah ada pada (diri) Rasulullah itu suri teladan yang baik bagimu (yaitu) bagi orang yang mengharap (rahmat) Allah dan (kedatangan) hari kiamat dan dia banyak menyebut Allah (QS. 33:21).

Keberadaan budaya daerah dan adat istiadat yang melahirkan pola kehidupan, tradisi dan bahasa daerah di Indonesia, merupakan aset yang tidak ternilai harganya, karena kebudayaan daerah itu sebagai bagian dari kebudayaan nasional yang ikut mempengaruhi pertumbuhan dan perkembangan kebudayaan secara nasional. Kekayaan khasanah sastra di Indonesia memang banyak dan luar biasa. Di Indonesia terdapat ratusan jenis bahasa daerah yang dengan sendirinya memiliki ratusan jenis sastra daerah. Kekayaan khasanah sastra Nusantara secara garis besar dapat dibagi tiga, yaitu: sastra lisan, sastra tulis dan sastra modern (Semi, 1993:3). Kehadiran sastra lisan dalam kehidupan bermasyarakat merupakan cerminan solidaritas dan pengenal identitas yang disampaikan secara lisan dan memiliki tujuan tertentu. Atmazaki (2007:138) menyatakan bahwa sastra lisan mempunyai banyak fungsi. Dengan sastra lisan, masyarakat purba atau nenek moyang umat manusia mengekspresikan gejolak jiwa dan renungannya tentang kehidupan. Emosi cinta diungkapkan lewat puisi-puisi sentimental, binatang buas dihadang dan dijinakkan dengan mantra-mantra. Asal-usul nama daerah, hukum adat, dan macammacam kearifan yang dicurahkan melalui berbagai mitos, dongeng, tombo, dan riwayat (Amin ,2013).

Cerita rakyat adalah sebagian kekayaan budaya dan sejarah yang dimiliki Bangsa Indonesia. Pada umumnya, cerita rakyat mengisahkan tentang suatu kejadian di suatu tempat atau asal muasal suatu tempat. Tokoh-tokoh yang dimunculkan dalam cerita rakyat umumnya diwujudkan dalam bentuk binatang, manusia maupun dewa. Fungsi cerita rakyat selain sebagai hiburan, juga bisa dijadikan suri tauladan terutama cerita rakyat yang mengandung pesanpesan pendidikan moral. Semi (1993:79) menjelaskan bahwa "cerita rakyat adalah sesuatu yang dianggap sebagai kekayaan milik rakyat yang kehadirannya di atas dasar keinginan untuk berhubungan sosial dengan orang lain. Dalam cerita rakyat dapat dilihat adanya berbagai tindakan berbahasa, guna untuk menampilkan adanya nilai-nilai dalam masyarakat". Cerita rakyat yang kaya akan nilai-nilai moral dan kearifan lokal, bisa dijadikan sarana komunikasi untuk mengajarkan nilai-nilai pendidikan tentang kehidupan kepada masyarakat. Kebudayaan daerah di Indonesia adalah bagian yang tidak terpisahkan dari khasanah kebudayaan nasional, karena kebudayaan daerah merupakan penunjang dalam pengembangan kebudayaan nasional. Hal ini merupakan suatu masalah yang tidak bisa dibiarkan begitu saja, jika tidak dibina maka akan berpengaruh kepada hilangnya nilai-nilai tradisi masyarakat.

Cerita rakyat sebagai bagian dari karya sastra juga memiliki unsur-unsur yang jalin menjalin, sehingga mendukung secara keseluruhan cerita yang ada. Di dalam cerita rakyat juga terdapat unsurunsur intrinsik dan ekstrinsik. Unsur-unsur intrinsik yang dibahas meliputi: tema, tokoh, alur cerita/plot, latar (setting), amanat Di samping struktur yang membangun sebuah karya sastra, maka di dalamnya juga terdapat nilai-nilai pendidikan yang dapat diambil oleh pembaca. Nilai adalah sesuatu yang berharga, bermutu, menunjukkan kualitas, dan berguna bagi manusia. Sesuatu itu bernilai berarti sesuatu itu berharga atau berguna bagi kehidupan manusia. Nilai sebagai kualitas yang independen akan memiliki ketetapan yaitu tidak berubah yang terjadi pada objek yang dikenai nilai. Persahabatan sebagai nilai (positif/ baik) tidak akan berubah esensinya manakala ada pengkhianatan antara dua yang bersahabat. Artinya, nilai adalah suatu ketetapan yang ada bagaimanapun keadaan di sekitarnya berlangsung (Gusnetti ,2015). 
Djamaris (1993:15) mengatakan bahwa cerita rakyat adalah golongan cerita yang hidup dan berkembang secara turun temurun dari satu generasi berikutnya. Disebut cerita rakyat karena cerita ini hidup di kalangan rakyat dan hampir semua lapisan masyarakat mengenal ceita itu. Cerita rakyat milik masyarakat bukan milik seorang. Cerita rakyat biasanya disampaikan secara lisan oleh tukang cerita yang hafal alur ceritanya. Itulah sebabnya cerita rakyat disebut sastra lisan. Hal ini sependapat dengan Danandjaja (1986:2) mengemukakan bahwa folklor adalah sebagian kebudayaan suatu kolektif yang tersebar dan diwariskan turuntemurun, diantara kolektif macam apa saja, secara tradisional dalam versi yang berbeda, baik dalam bentuk lisan maupun contoh yang disertai gerak isyarat atau alat pembantu pengingat (mnemonic device) (Melasarianti ,2015).

Penelitaian sebelumnya dilakukan oleh M. Arifin Arsyil Majid mengenai analisi nilai karakter pada dongen dan cerita rakyat, Hasil penelitian yang dilakukan oleh M. Arifin Arsyil Majid memiliki kelebihan yaitu bagaimana cara yang dilakukan oleh guru untuk menumbuhkan kebiasaan dan menanamkan kegemaran pada anak sekolah dasar. Menanamkan pembiasaan melalui sastra akan membentuk anak menjadi terbiasa dan melatih ketrampilan menulis, mendengarkan, berbicara, dan membaca melalui media sastra. Namun penelitian tersebut memiliki kelemahan bahwa untuk menerapkan pembiasaan bersastra membutuhkan waktu yang lama, disamping itu ketekunan dan pembelajaran yang inovatif harus selalu diterapkan, jika salah akan membuat suasana menjadi membosankan dan akan berdampak pada pembelajaran dan kegemaran bersastra selanjutnya, selain itu peneliti hanya menganalisis satu nilai yaitu nilai karakter saja. Untuk melengkapi hasil penelitian dari M. Arifin Arsyil Majid, peneliti menambahkan satu nilai pada buku cerita rakyat yaitu nilai spiritual dengan menumbuhkan nilai spiritual pada anak secara tidak langsung nilai karakter akan terbentuk, buku cerita rakyat juga bisa dijadikan sebagai media pembelajaran yang menyenangkan dan inovatif sehingga saat pembelajaran berlabgsung siswa tidak akan merasa bosan bahkan kegemaran untuk bersastra akan tertanam pada siswa.

Tujuan penelitian ini untuk mengetahui dan mendeskripsikan nilai-niali spiritual yang dapat membentuk karakter siswa dalam dongeng dan Buku Cerita Rakyat Joko Dolok Karya Wiradarsono, untuk mengetahui seberapa berpengaruhnya nilai spiritual dalam buku cerita yang dapat membentuk nilai karakter serta untuk mengetahui bagaimana sekolah menanamkan nilai karakter pada anak didik.

\section{Metode}

Metode yang akan digunakan peneliti adalah metode deskriptif kualitatif, karena metode deskriptif kualitatif menggunakan data yang tidak berupa angka, namun mendeskripsikan atau menjelaskan dalam bentuk kata-kata pada data yang diperoleh. Teknik pengumpulan data dilakukan dengan simak catat, observasi, wawancara, dokumentasi dan koesioner (angket). Pengecekan keabsahan data dengan cara meningkatkan ketekunan. Teknik analisi data menggunakan collecting data,reduksi data (data reducation), penyajian data (data display),dan verifikasi (coclution.Instrumen dalam penelitian ini adalah human instrumen (penelitian).

\section{Hasil dan Pembahasan}

Berdasarkan hasil penelitian, peneliti dapat memperoleh data penelitian dan pembahasan tentang Buku Cerita Rakyat Jaka Dolok Karya Wiradarsono memiliki 32 nilai spiritual dan nilai karakter, nilai spiritual sendiri tercermin melalui iman ibadah dan akhlak dan niali karakter tercermin melalui religius, jujur, toleran, disiplin, kerja keras, demokratis, semangat kebangsaan, cinta tanah air, bersahabat/ komunikatif, cinta damai, peduli lingkungan, peduli sosial dan tanggung jawab. Menggunakan bahasa jawa yang secara tidak langsung melestarikan budaya indonesia dan mengenalkan pembaca pada bahasa jawa, buku jaka dolok memiliki pesan yang sangat sederhana namun dapat membentuk karakter siswa. Isi cerita pada setiap bagian yang disajikan dari buku tersebut mudah dipahami, khususnya untuk orang tua anak-anak SD yang bisa membacakan cerita kepada anaknya, melalui mendengarkan anakanak bisa berimajinasi langsung kedalam jalan ceritanya. 
IVCEJ, Vol 2 No 1, Tahun 2019

p-ISSN: 2615-4684 e-ISSN: 2615-6938

1. Hasil Analisis Nilai Spiritual dalam Pembentukan Karakter pada Buku Cerita Rakyat Joko Dolok Karya Wiradarsono.

Tabel 1. Analisis Nilai Spiritual dalam pembentukan karakter pada buku cerita rakyat Joko Dolok Karya Wiradarsono

\begin{tabular}{|c|c|c|c|c|c|}
\hline \multicolumn{6}{|c|}{ Rubrik Indikator Nilai Spritual dan karakter } \\
\hline \multirow[t]{2}{*}{ No } & \multirow[t]{2}{*}{ Bagian } & \multicolumn{3}{|c|}{ Rubrik Indikator Spritual dan karakter } & \multirow[b]{2}{*}{$\begin{array}{c}\text { Jumlah } \\
\text { indikator } \\
\text { spiritual } \\
\text { dan } \\
\text { karakter }\end{array}$} \\
\hline & & Iman & Ibada & akhlak & \\
\hline 1 & Laire Putri Purbawati & $\begin{array}{c}2 \\
\text { (religius) }\end{array}$ & $\begin{array}{l}2 \text { (peduli sosial } \\
\text { dan tanggung } \\
\text { jawab) }\end{array}$ & 3 (religius) & 7 \\
\hline 2 & $\begin{array}{l}\text { Tamu Ing Kabupaten } \\
\text { Surabaya }\end{array}$ & & $\begin{array}{l}2 \text { (Religius, } \\
\text { kerja keras) }\end{array}$ & $\begin{array}{l}2 \text { (bersahabat/ } \\
\text { Komunikatif) }\end{array}$ & 4 \\
\hline 3 & Golek Jodo & $\begin{array}{c}1 \\
\text { (religius) }\end{array}$ & $\begin{array}{l}3 \text { (Religius, } \\
\text { kerja keras) }\end{array}$ & & 4 \\
\hline 4 & $\begin{array}{l}\text { Wangsulane putri } \\
\text { purbawati }\end{array}$ & $\begin{array}{c}1 \\
\text { (religius) }\end{array}$ & 1 (Mandiri) & 1 (demokratis) & 3 \\
\hline 5 & Sayembara diwiwti & & 1(Mandiri) & 1(demokratis) & 2 \\
\hline 6 & $\begin{array}{l}\text { Joko taruna ngelboni } \\
\text { sayembara }\end{array}$ & & 1 (kerja keras) & $\begin{array}{l}4 \text { (peduli sosial, } \\
\text { jujur, cinta } \\
\text { damai, religius) }\end{array}$ & 5 \\
\hline 7 & $\begin{array}{l}\text { Akal licike joko } \\
\text { taruna }\end{array}$ & & 1 (peduli Social) & 1 (toleran) & 1 \\
\hline 8 & $\begin{array}{l}\text { Perang tandhing sing } \\
\text { rame }\end{array}$ & & 1 (religius) & $\begin{array}{l}2 \text { (bersahabat, } \\
\text { Religius) }\end{array}$ & 3 \\
\hline 9 & Pelapuran palsu & & $\begin{array}{c}1 \text { (religius } \\
\text { demokratis) }\end{array}$ & 1 (jujur) & 2 \\
\hline 10 & $\begin{array}{l}\text { Asal mulane Joko } \\
\text { Dolok }\end{array}$ & & & 1 (Jujur) & 3 \\
\hline & Jumlah Total & 4 & 14 & 16 & 34 \\
\hline
\end{tabular}

Dari Tabel 1 menunjukan bahwa jumlah indikator keimanan sebanyak 4 buah dengan nilai karakter religius, indikator keibadahan sebanyak 14 buah dengan nilai karakter yaitu: peduli sosial, tanggung jawab, religius, kerja keras, mandiri, dan demokratis, dan indokator akhlak sebanyak 16 buah dengan nilai karakter yaitu: religius, bersahabat/ komunikatif, demokratis, peduli sosial, jujur, cinta damai, dan toleran.

2. Pengaruh nilai spiritual dalam buku cerita yang dapat membentuk nilai karakter.

Wawancara pertama yang dilaksanakan peneliti dengan narasumber guru kelas IV SD N Lamper Tengah 02 yaitu Bapak Adri Joko Suyanto, BA, beliau menjelaskan pengaruh nilai spiritual dalam buku cerita yang dapat membentuk nilai karakter tergantung pada lingkungan siswanya sendiri, karena seberapa banyak pun nilai spiritual yang ada dalam buku cerita rakyat tetapi jika lingkungan siswa kurang baik maka pengaruhnyapun tidak terlalu besar begitupun sebaliknya jika lingkungan siswa baik maka pengaruhnya akan besar. Beberapa nilai spiritual yang biasa ditemui pada buku cerita rakyat seperti lbadah dan akhlak yang seharusnya berpengaruh besar terhadap pembentukan karakter siswa namun pada kenyataanya siswa masih melakukan aktivitas sesuka hatinya tanpa mempertimbangkan nilai-nilai yang ada disekitarnya.

Wawancara kedua yang dilaksanakan peneliti dengan narasumber guru kelas III SD N Lamper Tengah 02 yaitu Ibu Dra. Endang Retno S, beliau menjelaskan pengaruh nilai spiritual dalam buku cerita rakyat yang dapat membentuk nilai karakter tergantung sebarapa persen nilai-nilai spiritual yang ada dalam buku cerita rakyat tersebut jika hanya ada $50 \%$ maka tidak akan terlalu berpengaruh sebaliknya jika mencapai $80 \%$ maka akan sangat berpengaruh. Untuk menerapkan nilai-niali spiritual yang terdapat dalam buku cerita rakyat bisanya guru akan 
mengulas kembali apa saja nilai spiritual yang ada dalam buku cerita rakyat tersebut kemudian guru akan menctohkannya didepan siswa, jadi tidak hanya membaca tetapi siswapun tau tindakan seprti apa yang bisa dilakukan agar dikemudian hari siswa dapat melaksanakannya.

Wawancara ketiga yang dilaksanakan peneliti dengan narasumber guru kelas V SD N Lamper Tengah 02 yaitu ibu Widi Kurniawati S.Pd, beliau menjelaskan pengaruh nilai spiritual dalam buku cerita rakyat yang dapat membentuk nilai karakter yang sangat besar karena dari buku cerita rakyat yang siswa baca secara langsung siswa dapat memahaminya dari pada siswa harus menganalisa kehidupan sehari-hari, karena buku cerita rakyat secara tidak langsung bisa dijadikan contoh nyata yang ada dikehidupan. Peran Tokoh-tokoh yang memiliki nilah spiritula yang bisa dicontoh oleh anak-anak yang terdapat pada cerita rakyat secara tidak langsung akan membentuk karakter pada anak.

3. Kiat-kiat sekolah dalam menanamkan nilai karakter pada anak didik.

Berdasarkan hasil wawancara yang dilakukan di SD N Lamper Tengah 02 menurut beberapa narasumber untuk menanamkan nilai karakter pada anak didik yaitu bisa melalui tiga cara yang pertama sebelum pembelajaran, saat jam pembelajaran dan diluar jam pembelajaran. Yang pertama sebelum memulai pembeajaran siswa diperintahkan untuk datang tepat waktu (disiplin), menyambut siswa didepan gerbang dengan menanyakan kabar (bersahabat/ komunikatif) dan berbaris sebelum masuk kelas (disiplin). Yang kedua adalah saat jam pelajaran berlangsung, saat jam pelajaran berlangsunglah guru mempunyai banyak peran untuk menanamkan dan membentuk nilai karakter pada siswa seperti mengawali pembelajaran dengan berdoa (religius), menyanyikan lagu-lagu nasional dan lagu-lagu daerah (cinta tanah air), berdiskusi dengan teman sejawat (toleran), mengerjakan tugas (kerja keras), mengumpulkan tugas tepat waktu (disiplin) dan masih banyak lagi. Kemudian yang ketiga yaitu diluar jam pelajaran, meski diluar jam pelajaran pihak sekolah masih bisa menanamkan karakter pada siswa yaitu dengan adanya ekstrakurikulier yang dilaksanakan secara rutin seperti ekstrakurikuler tari (cinta tanah air), pramuka yang mengajarkan tentang disiplin, rebana seni musik islam (religius), kiroati (religius), dan latihan upacar (semangat kebangsaan), dengan adanya ekstrakurikuler akan membuat siswa lebih akrab pada siswa lainnya (bersahabat/ komunikatif). Diluar ekstrakurikuler pun sekolah memiliki kegiatan rutinan yaitu sholat dhuhur berjamaah yang dilaksanakan siswa dari kelas 3-6 (religius). Melalui tiga cara tersebut dalam menanamkan nilai karakter pada siswa, maka pembentukkan karakter pada siswa akan lebih mudah.

\section{Simpulan dan Saran}

Berdarkan hasil penelitian daN pembahasan yang telah diuraikan di atas dapat disimpulkan bahwa dalam buku Cerita Rakyat Joko Dolok Karya Wiradarsono Terbitan Kharisma tahun 2014 dan memiliki 134 halaman mengandung 32 nilai spiritual yang dapat membentuk karakter anak-anak. Nilai-nilai tersebut dilihat dari kutipan dalam penokohan dan dibuktikan dari indikator iman, ibadah dan akhlak, serta indikator nilai-nilai karakter (religius, jujur, toleran, disiplin, kerja keras, demokratis, semangat kebangsaan, cinta tanah air, bersahabat/ komunikatif, cinta damai, peduli lingkungan, peduli sosial dan tanggung jawab). Cerita tersebut dikemas dengan sangat sederhana dan mudah dipahami meski menggunakan bahasa jawa serta sangat cocok untuk menjadi bahan bacaan anak-anak pada era milenial atau bahkam orang tua yang ingin mendongeng untuk anaknya.

Pengaruh nilai spiritual dalam buku cerita rakyat joko dolok pada pembentukkan anak tergantung dari beberapa hal yaitu lingkungan pada siswanya, seberapa banyak nilai spiritual yang ada dalam buku tersebut dan isi dari cerita rakyat tersebut. Dalam menanamkan nilai karakter pada anak-anak ada tiga cara yaitu yang pertama sebelum pembelajaran dimulai, yang kedua saat pembelajaran dilaksanakan dan yang ketiga saat diluar jam pelajaran.

Setelah melakukan analisis nilai spiritual dalam pembentukan karakter pada buku Cerita Rakyat Jaka Dolok, penulis memberikan saran yang dapat dijadikan rekomendasi untuk berbagai pihak diantaranya untuk guru dan untuk orang tua. Beberapa saran yang ingin penulis sampaikan diantaranya:

1. Untuk guru agar lebih memanfaatkan cerita rakyat dan nilai-nilai luhur terlebih nilai spiritual dalam sarana edukasi disekolah karena dapat membentuk karakter pada nak-anak. selain itu cerita rakyat adalah hiburan yang menjaga kelestarian budaya bangsa indonesia dan melalui cerita rakyat dapat meningkatkan budaya membaca bagi anak-anak disekolah. 
IVCEJ, Vol 2 No 1, Tahun 2019

p-ISSN: 2615-4684 e-ISSN: 2615-6938

2. Untuk orang tua agar lebih selektif dalam memfasilitasi anak-anak pada ranah hiburan. Dongeng juga merupakan hiburan yang menyenangkan lagi positif bagi perkembangan moral, mental dan spiritual anak. selain itu melalui mendongeng orang tua bisa lebih dekat dengan anaknya.

\section{Daftar Pustaka}

Al-Qur"an dan terjemahnya. 2006. Departemen Agama Republik Indonesia. Pustaka Agung harapan.

Amin ,Irzal (2013). Cerita Rakyat Penamaan Desa Di Kerinci: Kategori dan Fungsi Sosial Teks . Jurnal Bahasa, Sastra dan Pembelajaran Volume 1 Nomor 1, Februari 2013

Edy, Raheni dkk. 2013. Model Pendidikan Budi Pekerti Berbasis Cerita Anak untuk Penanaman Nilai Etis-Spiritual. Jurnal UNS. Vol.12, No. 2, edisi Oktober.

Gusviani, Evi. 2016. Analisis Kemunculan Sikap Spiritual Dan Sikap Sosial Dalam Kegiatan Pembelajaran Ipa Kelas IV Sd Yang Menggunakan Ktsp Dan Kurikulum 2013 EduHumaniora: Jurnal Pendidikan Dasar Vol. 8. No.1 Januari 2016 Hal 96-100

Gusnetti ,Syofiani ,Isnanda (2015). Struktur Dan Nilai-Nilai Pendidikan Dalam Cerita Rakyat Kabupaten Tanah Datar Provinsi Sumatera Barat . Jurnal Penelitian Bahasa dan Sastra Indonesia V1.i2 ISSN: 2442-8485 E-ISSN: 2460-6319

Kristanto, M. 2014. Pemanfaatan Cerita Rakyat Sebagai Penanaman Etika untuk Membentuk Pendidikan Karakter Bangsa. Jurnal UPI. Vol.1, No.1, edisi April.

Majid, M. Arifin Arsyil. 2015. Analisis Nilai Karakter Dongeng dan Cerita Rakyat Indonesia pada Buku "Dongeng dan Cerita Rakyat Nusantara paling Melegenda" Tulisan Ajeng Restiyani 2015. Skripsi Semarang: Universitas PGRI Semarang.

Matthew, Michael Huberman. 1992. Analisis Data Kualitatif. Jakarta: Universitas Indonesia (UI Perss).

Melasarianti , Lalita (2015). Membentuk Karakter Anak Sesuai Prinsip Pancasila Melalui Cerita Rakyat . Jurnal Lingua Idea Vol 6, No 1, Juni 2015

Moleong, Lexy J. 2006. Metodologi Penelitian Kualitatif. Bandung: Penerbit PT Remaja Rosdakarya.

Munirah (2015). Sistem Pendidikan Di Indonesia: Antara Keinginan Dan Realita . Jurnal Auladuna, Vol. 2 No. 2 Desember 2015

Ngafifi, Muhamad. 2014. Kemajuan Teknologi Dan Pola Hidup Manusia Dalam Perspektif Sosial Budaya. Jurnal Pembangunan Pendidikan: Fondasi dan Aplikasi Volume 2, Nomor 1.

Nashir, Haedar. 2013. Pendidikan Karakter Berbasis Agama \& Budaya. Yogyakarta: Multi Presindo

Nurkholis (2013). Pendidikan Dalam Upaya Memajukan Teknologi . Jurnal Kependidikan, Vol. 1 No. 1 Nopember 2013

Nurgiyantoro, Burhan. 2010. Teori Pengkajian Fiksi. Yogyakarta: FKIP Universitas Sarjana wiyata Taman siswa.

Parmini, Ni Putu. 2015. Eksistensi Cerita Rakyat dalam Pendidikan Karakter Siswa SD di Ubud. Jurnal Kajian Bali. Vol.05, No.02, edisi Oktober. 
IVCEJ, Vol 2 No 1, Tahun 2019

p-ISSN: 2615-4684 e-ISSN: 2615-6938

Rachman, Abd Abror. 2009. Pantun Melayu: Titik Temu Islam dan Budaya Lokal Nusantara. Yogyakarta: LkiS Yogyakarta.

Saptono. 2011. Dimensi-Dimensi Pendidikan Karakter: Wawasan, Strategi, dan Langkah Praktis. Jakarta: Erlangga Group.

Syafri, Ulil Amri. 2012. Pendidikan Karakter Berbasis Al-Qur'an. Jakarta: Rajawali Pers.

Wiradarsono, Hadi. Jaka Dolok. Surakarta: Kharisma.

Yaum, Muhammad. 2014. Pendidikan Karakter: Landasan, Pilar, dan Implementasi. Jakarta: Pernadamedia Group. 